\title{
Multiscale architectures boosting thermoelectric performance of copper sulfide compound
}

\author{
Xin-Qi Chen, Sheng-Jie Fan, Chao Han, Tian Wu, Lian-Jun Wang, \\ Wan Jiang, Wei Dai*ib, Jian-Ping Yang*(D)
}

Received: 19 September 2020/Revised: 21 October 2020/Accepted: 24 November 2020/Published online: 28 February 2021

(C) Youke Publishing Co., Ltd. 2021

\begin{abstract}
Owing to their high performance and earth abundance, copper sulfides $\left(\mathrm{Cu}_{2-x} \mathrm{~S}\right)$ have attracted wide attention as a promising medium-temperature thermoelectric material. Nanostructure and grain-boundary engineering are explored to tune the electrical transport and phonon scattering of $\mathrm{Cu}_{2-x} \mathrm{~S}$ based on the liquid-like copper ion. Here multiscale architecture-engineered $\mathrm{Cu}_{2-x} \mathrm{~S}$ are fabricated by a room-temperature wet chemical synthesis combining mechanical mixing and spark plasma sintering. The observed electrical conductivity in the multiscale architecture-engineered $\mathrm{Cu}_{2-x} \mathrm{~S}$ is four times as much as that of the $\mathrm{Cu}_{2-x} \mathrm{~S}$ sample at $800 \mathrm{~K}$, which is attributed to the potential energy filtering effect at the new grain
\end{abstract}

Xin-Qi Chen and Sheng-Jie Fan have contributed equally to this work.

Supplementary Information The online version of this article (https://doi.org/10.1007/s12598-020-01698-6) contains supplementary material, which is available to authorized users.

X.-Q. Chen, T. Wu, W. Dai*

School of Physics and Mechanical and Electrical Engineering,

Hubei Engineering Technology Research Center of

Environmental Purification Materials, Institute of Materials

Research and Engineering, Hubei University of Education,

Wuhan 430205, China

e-mail: daiwei@hue.edu.cn

\section{S.-J. Fan, L.-J. Wang, W. Jiang, J.-P. Yang*}

State Key Laboratory for Modification of Chemical Fibers and Polymer Materials, College of Materials Science and Engineering, Donghua University, Shanghai 201620, China e-mail: jianpingyang@dhu.edu.cn

\section{Han}

Institute for Superconducting and Electronic Materials, University of Wollongong, North Wollongong, NSW 2500, Australia boundaries. Moreover, the multiscale architecture in the sintered $\mathrm{Cu}_{2-x} \mathrm{~S}$ increases phonon scattering and results in a reduced lattice thermal conductivity of $0.2 \mathrm{~W} \cdot \mathrm{m}^{-1} \cdot \mathrm{K}^{-1}$ and figure of merit $(z T)$ of 1.0 at $800 \mathrm{~K}$. Such a $z T$ value is one of the record values in copper sulfide produced by chemical synthesis. These results suggest that the introduction of nanostructure and formation of new interface are effective strategies for the enhancement of thermoelectric material properties.

Keywords Thermoelectric properties; Copper sulfides; Room-temperature synthesis; Nanostructure;

Semiconductor

\section{Introduction}

Thermoelectric (TE) technology, which can directly convert waste heat into useful electricity, plays a crucial part in a global sustainable energy solution for the environmental contamination and energy crisis [1-3]. The efficiency of TE devices is dominated by the performance of selected TE material, which is indexed by the dimensionless figure of merit $(z T)=S^{2} \sigma T / \kappa$, where $S, \sigma, T$, and $\kappa$ are the Seebeck coefficient, electrical conductivity, absolute temperature, and thermal conductivity, respectively [4-6]. To approach high TE device efficiency, materials with high $z T$ values are desired [7, 8]. A good TE material should simultaneously have a large $S$ as semi-conductors, a high $\sigma$ as metals, and a low $\kappa$ as glasses [9-11]. However, these three TE parameters are synergistic with each other. It is hard to combine all these features in a single material [12]. Specifically, $\sigma$ and $S$ can hardly increase simultaneously as these two parameters are coupled via carrier concentration 
$[13,14]$. Besides, the reduction of $\kappa$ often degrades the carrier mobility and thus $\sigma$ [15-17]. Conflicts between these properties impede the limitless enhancement of $z T$, where a compromise is necessary to optimize $z T$.

Copper sulfides were identified as a promising TE material since 1827 [18-20]. With low $\kappa$ and high TE performance, copper sulfides attract extensive research interest [21-27]. Currently, the field of copper sulfides is mainly focusing on the reduction of $\kappa$ by designing intrinsically low-dimensional crystalline structures and on the increase of power factor $\left(\mathrm{PF}=S^{2} \sigma\right)$ by enhancing electron transport properties [28, 29]. Cubic copper sulfide with liquid $\mathrm{Cu}$-ion has intrinsic low lattice thermal conductivity $\left(\kappa_{\mathrm{L}}\right)$ in high-temperature regions [30, 31], which is the main reason for intrinsically low $\kappa_{\mathrm{L}}$ of copper sulfides $[32,33]$. For example, an extremely low $\kappa_{\mathrm{L}}$ below $0.35 \mathrm{~W} \cdot \mathrm{m}^{-1} \cdot \mathrm{K}^{-1}$ and a high $z T$ of 1.7 at $1000 \mathrm{~K}$ has been reported in $\mathrm{Cu}_{2-x} \mathrm{~S}$ [34]. Besides, Fe dopants remarkably decrease $\kappa$ without compromising PF, leading to improved $z T$ of 0.8 at $750 \mathrm{~K}$ for $\mathrm{Cu}_{1.80} \mathrm{Fe}_{0.048} \mathrm{~S}$, which is about three times that of $\mathrm{Cu}_{1.80} \mathrm{~S}$ [35]. In the aspect of enhancing PF, electron transport abilities play a key role, which can be achieved by tuning the compositions in copper sulfide compound, such as doping, hybridization, and designing mosaic architecture [36-41]. It was demonstrated that Nadoped $\mathrm{Cu}_{9} \mathrm{~S}_{5}$ shows remarkable low $\kappa$ ranging from 0.68 to $2.3 \mathrm{~W} \cdot \mathrm{m}^{-1} \cdot \mathrm{K}^{-1}$ due to the weak-binding copper ions in the quasi-molten state, where $\mathrm{Na}_{0.01} \mathrm{Cu}_{9} \mathrm{~S}_{5}$ eventually achieves a $z T$ value of 1.1 at $773 \mathrm{~K}$ [36]. Se doping was reported to enhance $\mathrm{PF}$ of $\mathrm{Cu}_{2} \mathrm{~S}$ by modifying the band structure and a peak $z T$ value of 0.74 was achieved at $723 \mathrm{~K}$ in $\mathrm{Cu}_{2} \mathrm{~S}_{0.9} \mathrm{Se}_{0.1}$, which is $131 \%$ higher than that $(z T$ value of 0.32 ) of the pristine $\mathrm{Cu}_{2} \mathrm{~S}$ [37]. Hybridizing the threedimensional interface structure of graphene and $\mathrm{Cu}_{2-x} \mathrm{~S}$ can enlarge $S$. Experiments show that a high $z T$ value and $\mathrm{PF}$ reached 1.56 and $1197 \mu \mathrm{W} \cdot \mathrm{m}^{-1} \cdot \mathrm{K}^{-2}$ at $873 \mathrm{~K}$ in $0.75 \mathrm{wt} \% \mathrm{G} / \mathrm{Cu}_{2-x} \mathrm{~S}$ sample [38]. A designed mosaic nanostructured $\mathrm{Cu}_{2} \mathrm{~S}_{0.52} \mathrm{Te}_{0.48}$ shows multiform effects to tune TE properties, where electrons are freely transferred within the quasi-single crystal structural frames while phonons are strongly scattered by lattice strains or interfaces [39]. The optimization of the electron and phonon transport is simultaneously promoted to reach a peak $z T$ value of 2.1 at $1000 \mathrm{~K}$ in mosaic nanostructured $\mathrm{Cu}_{2} \mathrm{~S}_{0.52} \mathrm{Te}_{0.48}$. It should be mentioned that controlling and fine-tuning of the mesoscale architectures in nanostructured TE materials can scatter heat-carrying phonons with long mean free paths, leading to the maximum reduction of $\kappa_{\mathrm{L}}$ [42]. This motivates us to design the multiscale architectures in copper sulfides by simultaneously employing nanostructure engineering and grain-boundary engineering. Moreover, it is still necessary to explore low-cost and practical strategies to achieve the reduction of $\kappa_{\mathrm{L}}$ and enhancement of PF, simultaneously.

In this work, the micro- and nano- $\mathrm{Cu}_{2-x} \mathrm{~S}$ particles are fabricated by an ambient wet chemical method. The multiscale architecture-engineered $\mathrm{Cu}_{2-x} \mathrm{~S}$ is prepared by mechanical mixing of these two kinds of particles and spark plasma sintered (SPS) into pellets. The obvious increase of $\sigma$ in the multiscale architecture-engineered $\mathrm{Cu}_{2-x} \mathrm{~S}$ is by 4 times than that of the micro- $\mathrm{Cu}_{2-x} \mathrm{~S}$ at $800 \mathrm{~K}$ due to the formation of new grain boundaries and carrier mobility. The $\kappa_{\mathrm{L}}$ (below $0.5 \mathrm{~W} \cdot \mathrm{m}^{-1} \cdot \mathrm{K}^{-1}$ ) of multiscale architecture-engineered $\mathrm{Cu}_{2-x} \mathrm{~S}$ is secured by nanoparticles in the multiscale architecture inducing phonon scattering. A $z T$ value of 1.0 has been achieved at $800 \mathrm{~K}$ in the multiscale architecture-engineered $\mathrm{Cu}_{2-x} \mathrm{~S}$, revealing that the design of multiscale architectures improves the TE performance of $\mathrm{Cu}_{2-x} \mathrm{~S}$.

\section{Experimental}

\subsection{Chemicals}

Chemical reagents, including $\mathrm{Cu}$ nano-powder $(25 \mathrm{~nm}$, $\geq 99.5 \%), \quad \mathrm{S}$ powder $(\geq 99.5 \%), \quad$ 2-Mercaptoethanol $(\geq 99.0 \%)$, and hydrazine solution (35 wt $\%$ ), were ordered from Sigma-Aldrich. $\mathrm{Cu}$ powder (250-300 mesh, $\geq 99.7 \%$ ), $\mathrm{NaOH}(\geq 96.0 \%)$, and anhydrous ethanol were ordered from Sinopharm Chemical Reagent Co., Ltd.

\subsection{Synthesis of micro-/nano- $\mathrm{Cu}_{2-x} \mathrm{~S}$ particles}

In a typical synthesis [43, 44], $7.626 \mathrm{~g}(0.12 \mathrm{~mol}) \mathrm{Cu}$ micro-powder or $\mathrm{Cu}$ nano-powder, $3.848 \mathrm{~g}(0.12 \mathrm{~mol}) \mathrm{S}$ powder, and $200 \mathrm{ml}$ of anhydrous ethanol were added into a $500-\mathrm{ml}$ beaker. Then $25.2 \mathrm{ml}(0.36 \mathrm{~mol})$ of 2-mercaptoethanol and $2 \mathrm{ml}$ of $\mathrm{NaOH}\left(7 \mathrm{~mol} \cdot \mathrm{L}^{-1}\right)$ were added into the beaker with gentle stirring for one day. The formed dark brown precipitates were separated from the solution and redispersed in the hydrazine solution $(200 \mathrm{ml})$ with stirring for $20 \mathrm{~min}$. The precipitates were filtered, purified with distilled water and ethanol several times, and dried at $50{ }^{\circ} \mathrm{C}$ in oven.

\subsection{Synthesis of multiscale architecture-engineered $\mathrm{Cu}_{2-x} \mathrm{~S}$}

The micro- and nano- $\mathrm{Cu}_{2-x} \mathrm{~S}$ particles with the ratios of $a$ to $b(a: b=3: 1,1: 1,1: 3)$ were mixed by mechanical mixing. Then the mixture particles were annealed under $\mathrm{Ar} / \mathrm{H}_{2}$ atmosphere at $700{ }^{\circ} \mathrm{C}\left(10{ }^{\circ} \mathrm{C} \cdot \mathrm{min}^{-1}\right)$ for $2 \mathrm{~h}$. After ground, the mixture particles were sintered by SPS at $420{ }^{\circ} \mathrm{C}$ for $5 \mathrm{~min}$ in a $\Phi 12 \mathrm{~mm}$ graphite die under $70 \mathrm{MPa}$. 


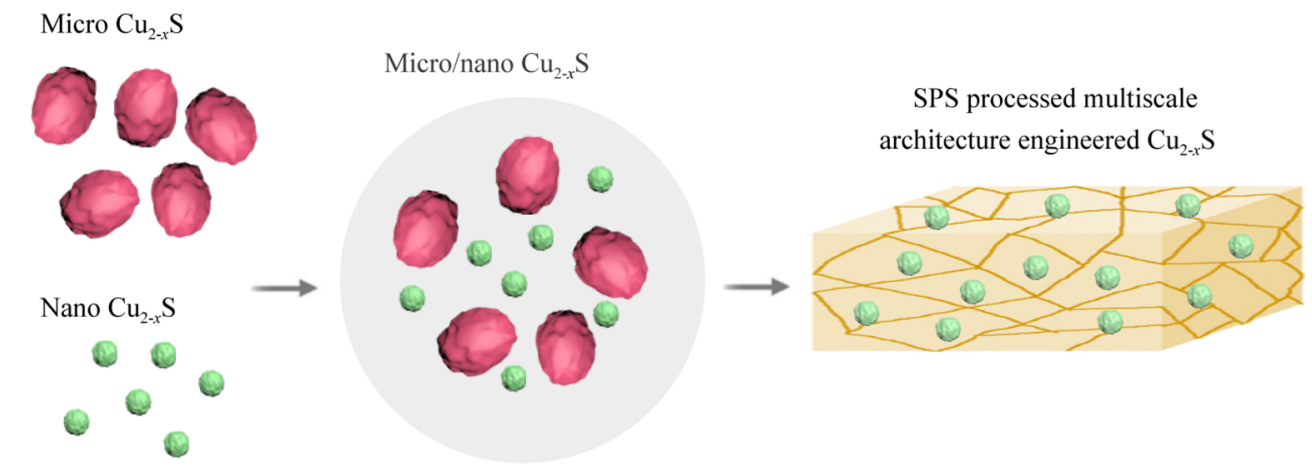

Fig. 1 Schematic illustration of formation process for multiscale architecture-engineered $\mathrm{Cu}_{2-x} \mathrm{~S}$

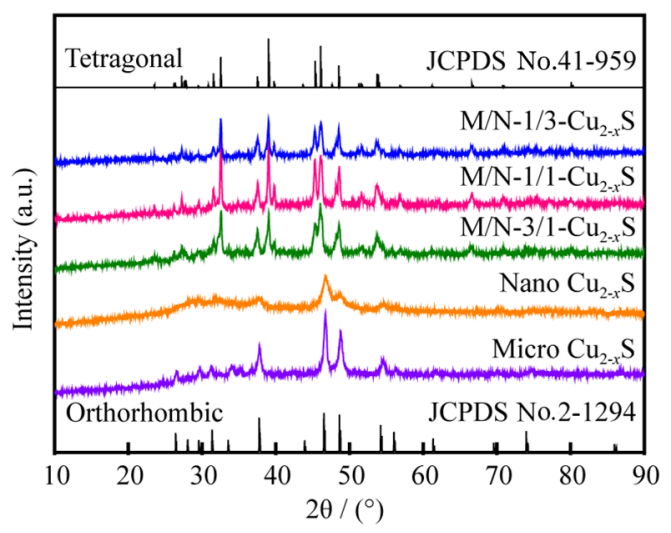

Fig. 2 XRD patterns of as-prepared micro- $\mathrm{Cu}_{2-x} \mathrm{~S}$ and nano $\mathrm{Cu}_{2-x} \mathrm{~S}$ particles, and annealed multiscale architecture-engineered $\mathrm{Cu}_{2-x} \mathrm{~S}$ samples

To express expediently in the following content, the multiscale architecture-engineered $\mathrm{Cu}_{2-x} \mathrm{~S}$ with different ratios of $a$ to $b$ were shortly named $\mathrm{M} / \mathrm{N}-3 / 1-\mathrm{Cu}_{2-x} \mathrm{~S}, \mathrm{M} / \mathrm{N}-1 / 1-$ $\mathrm{Cu}_{2-x} \mathrm{~S}$, and $\mathrm{M} / \mathrm{N}-1 / 3-\mathrm{Cu}_{2-x} \mathrm{~S}$, respectively.

\subsection{Characterization}

X-ray diffraction (XRD) patterns for all $\mathrm{Cu}_{2-x} \mathrm{~S}$ samples were detected using $\mathrm{Cu} \mathrm{K} \alpha$ radiation $(\lambda=0.15406 \mathrm{~nm})$ by a Rigaku D/Max-2550 PC diffractometer (Tokyo, Japan). $\mathrm{X}$-ray photoelectron spectroscopy (XPS) was used to understand the surface chemical composition of the samples. Scanning electron microscopy (SEM) and transmission electron microscopy (TEM) images of all the samples were collected by a Hitachi S-4800 (Japan) microscope and a JEOL JEM-2100F microscope, respectively.

\subsection{Thermoelectric measurements}

The resultant multiscale architecture-engineered $\mathrm{Cu}_{2-x} \mathrm{~S}$ pellets were cut and polished as cuboids with a size of $\sim 2 \mathrm{~mm} \times 3 \mathrm{~mm} \times 10 \mathrm{~mm}$ for electrical property measurement and as a disk shape with a diameter of $10 \mathrm{~mm}$ and a thickness of $1 \mathrm{~mm}$ for thermal diffusion measurement. The $\sigma$ and $S$ were measured simultaneously under a $\mathrm{He}$ atmosphere by the ZEM-3 (ULVAC-RIKO, Japan). The thermal diffusivity $(D)$ was measured using a Netzsch LFA427 (Germany). The heat capacity $\left(C_{\mathrm{p}}\right)$ was measured using a NETZSCH DSC 204F1 Phoenix. The test temperature ranges from room temperature to $800 \mathrm{~K}$. The densities $(\rho)$ were measured by the Archimedes method. The $\kappa$ was calculated according to the relationship $\kappa=\rho C_{\mathrm{p}} D$. The carrier concentration $\left(n_{\mathrm{H}}\right)$ and carrier mobility $\left(\mu_{\mathrm{H}}\right)$ at room temperature were measured using the Hall measurement system (Lake Shore 8400).

\section{Results and discussion}

\subsection{Phase and microstructure}

Figure 1 illustrates the typical process for fabricating the multiscale architecture-engineered $\mathrm{Cu}_{2-x} \mathrm{~S}$, in which the micro- and nano- $\mathrm{Cu}_{2-x} \mathrm{~S}$ particles with different ratios were mixed by mechanical mixing and sintered by SPS. The XRD patterns of as-prepared micro, nano $\mathrm{Cu}_{2-x} \mathrm{~S}$ particles, and multiscale architecture-engineered $\mathrm{Cu}_{2-x} \mathrm{~S}$ samples are shown in Fig. 2. The XRD peaks of both asprepared micro- and nano- $\mathrm{Cu}_{2-x} \mathrm{~S}$ samples can be well assigned to the planes of the orthorhombic $\mathrm{Cu}_{2} \mathrm{~S}$ (JCPDS No. 2-1294). The diffraction peak of the nano $\mathrm{Cu}_{2-x} \mathrm{~S}$ sample is wider than that of the micro- $\mathrm{Cu}_{2-x} \mathrm{~S}$ sample, indicating that the particle size of the micro- $\mathrm{Cu}_{2-x} \mathrm{~S}$ sample is large. After the annealing process, all peaks of the multiscale architecture-engineered $\mathrm{Cu}_{2-x} \mathrm{~S}$ samples consistent with the standard peaks of the tetragonal $\mathrm{Cu}_{1.81} \mathrm{~S}$ (JCPDS No. 41-959). An orthorhombic to tetragonal phase transition in the high-temperature annealing process is the intrinsic properties of $\mathrm{Cu}_{2-x} \mathrm{~S}$ [45-49]. Further confirmation of this phase transition was determined by measurement of the $C_{\mathrm{p}}$ curve, which has a prominent peak at $373 \mathrm{~K}$ (Figure S1 in Supporting Information). The tetragonal 

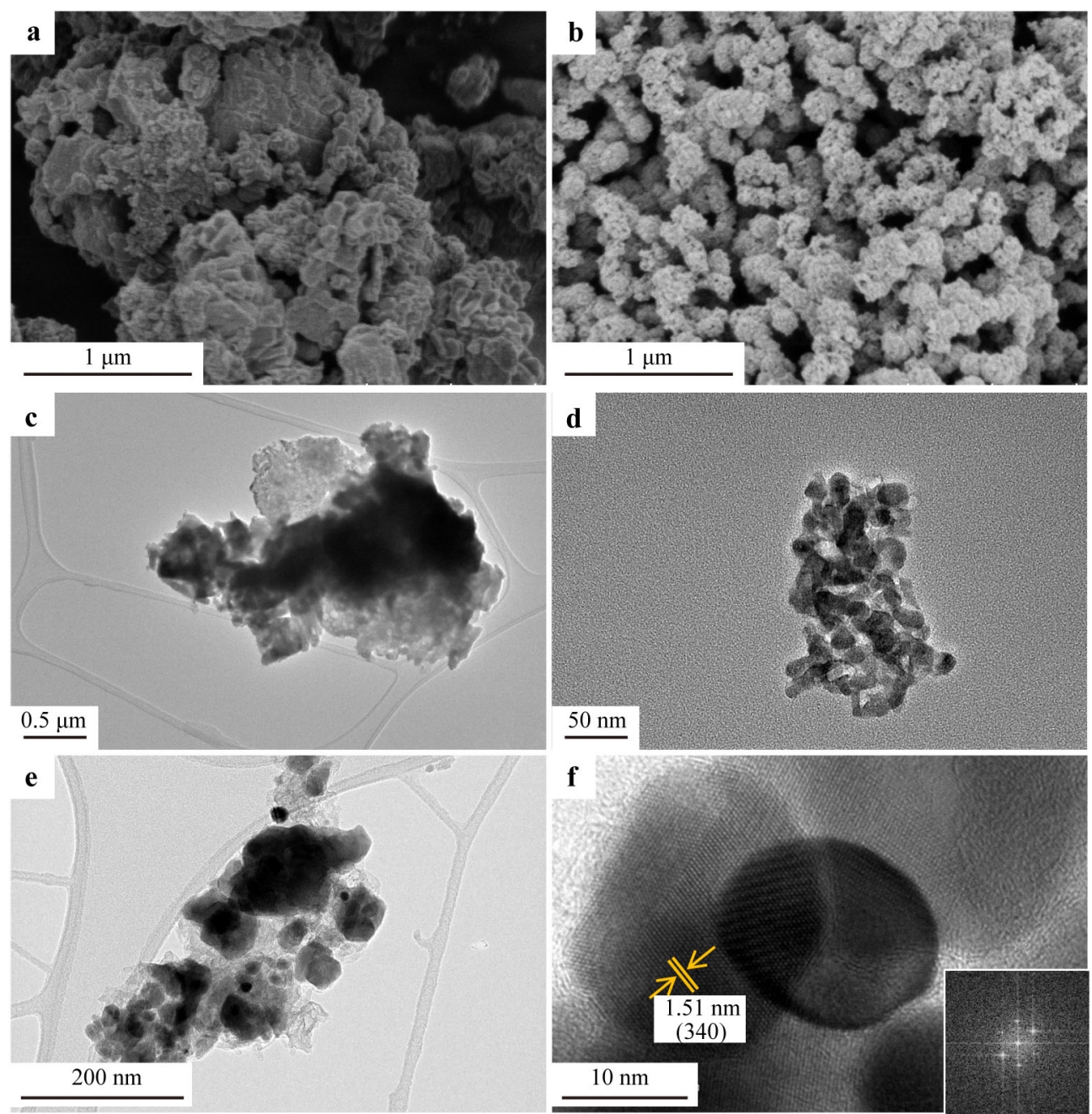

Fig. 3 SEM images and TEM images of $\mathbf{a}, \mathbf{c}$ as-prepared micro- $\mathrm{Cu}_{2-x} \mathrm{~S}$ sample and $\mathbf{b}$, $\mathbf{d}$ as-prepared nano $\mathrm{Cu}_{2-x} \mathrm{~S}$ sample; e TEM image of annealed $\mathrm{M} / \mathrm{N}-1 / 3-\mathrm{Cu}_{2-x} \mathrm{~S}$ sample; $\mathbf{f}$ HRTEM image of annealed $\mathrm{M} / \mathrm{N}-1 / 3-\mathrm{Cu}_{2-x} \mathrm{~S}$ sample and (inset) FFT pattern

phase was retained after the SPS process and TE measurements, which were confirmed by XRD results (Figure S2).

The typical SEM images and low-resolution TEM images indicate that the micro- $\mathrm{Cu}_{2-x} \mathrm{~S}$ sample is irregular particles with a rough surface on the micron scale (Fig. 3a, c), and the nano $\mathrm{Cu}_{2-x} \mathrm{~S}$ sample is agglomerating round particles with the diameters ranging from 10 to $20 \mathrm{~nm}$ (Fig. 3b, d). The reaction mechanism of $\mathrm{Cu}_{2-x} \mathrm{~S}$ is that $\mathrm{Cu}$ particles are used as sacrificial templates during the preparation of the micro- and nano- $\mathrm{Cu}_{2-x} \mathrm{~S}$ particles [50]. In the reaction, thiol molecules were directionally adsorbed on the surface of $\mathrm{Cu}$ particles and $\mathrm{S}$ molecules were dissolved in 2-Mercaptoethanol to form thiosulfide, then $\mathrm{Cu}$ / thiol groups reacted with thiosulfide to finally form $\mathrm{Cu}_{2-x} \mathrm{~S}$. Thus the particle size of $\mathrm{Cu}_{2-x} \mathrm{~S}$ is determined by the size of self-sacrificed $\mathrm{Cu}$ template. Employing the $\mathrm{M} / \mathrm{N}-1 / 3-\mathrm{Cu}_{2-x} \mathrm{~S}$ sample as an example, nanoparticles remained in multiscale architecture-engineered $\mathrm{Cu}_{2-x} \mathrm{~S}$ (Fig. 3e) after SPS. The high-resolution TEM (HRTEM) images show the nanoparticles and the interface between nanoparticles in the $\mathrm{M} / \mathrm{N}-1 / 3-\mathrm{Cu}_{2-x} \mathrm{~S}$ sample. The lattice fringes have a spacing of $1.51 \mathrm{~nm}$ (Fig. 3f), which matches well with the (340) planes of the tetragonal phase $\mathrm{Cu}_{2-x} \mathrm{~S}$. The inset fast Fourier transforms (FFT) pattern in Fig. $3 \mathrm{f}$ confirms this tetragonal structure.

Due to the $\mathrm{Cu}_{2} \mathrm{~S}$ is easy to oxidize [45], XPS results were used to calculate the ratios of $\mathrm{Cu}$ with different valence states in the multiscale architecture-engineered $\mathrm{Cu}_{2-x} \mathrm{~S}$ samples (Fig. 4). The XPS spectra of $\mathrm{Cu} 2 \mathrm{p}$ illustrate the presence of both $\mathrm{Cu}^{+}$and $\mathrm{Cu}^{2+}$ in these samples (Fig. 4a). The calculated ratio of $\mathrm{Cu}^{+} / \mathrm{Cu}^{2+}$ increases from 8.1, 12.9 to 14.1 as the fraction of nanoparticles increased indicating a reduced amount of $\mathrm{Cu}$ vacancies. The $S 2 p$ peak from $\mathrm{S}^{2-}$ is located around $162.0 \mathrm{eV}$ for all three multiscale architecture of $\mathrm{Cu}_{2-x} \mathrm{~S}$ 

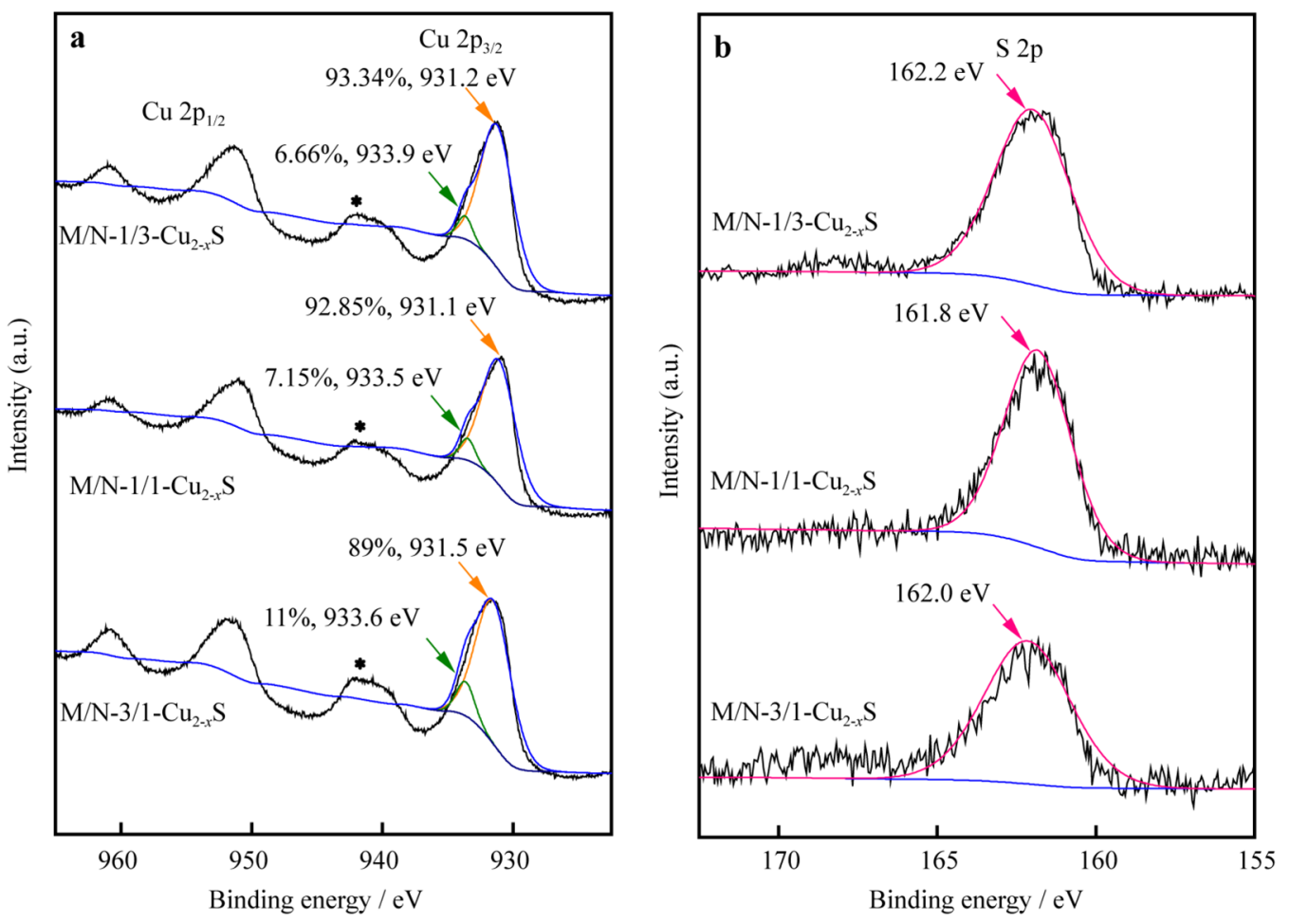

Fig. 4 XPS spectra of $\mathbf{a} \mathrm{Cu} 2 \mathrm{p}$ and $\mathbf{b} \mathrm{S} 2 \mathrm{p}$ of multiscale architecture-engineered $\mathrm{Cu}_{2-x} \mathrm{~S}$ (black asterisks in a marking satellite peak of $\mathrm{Cu}^{2+}$ )
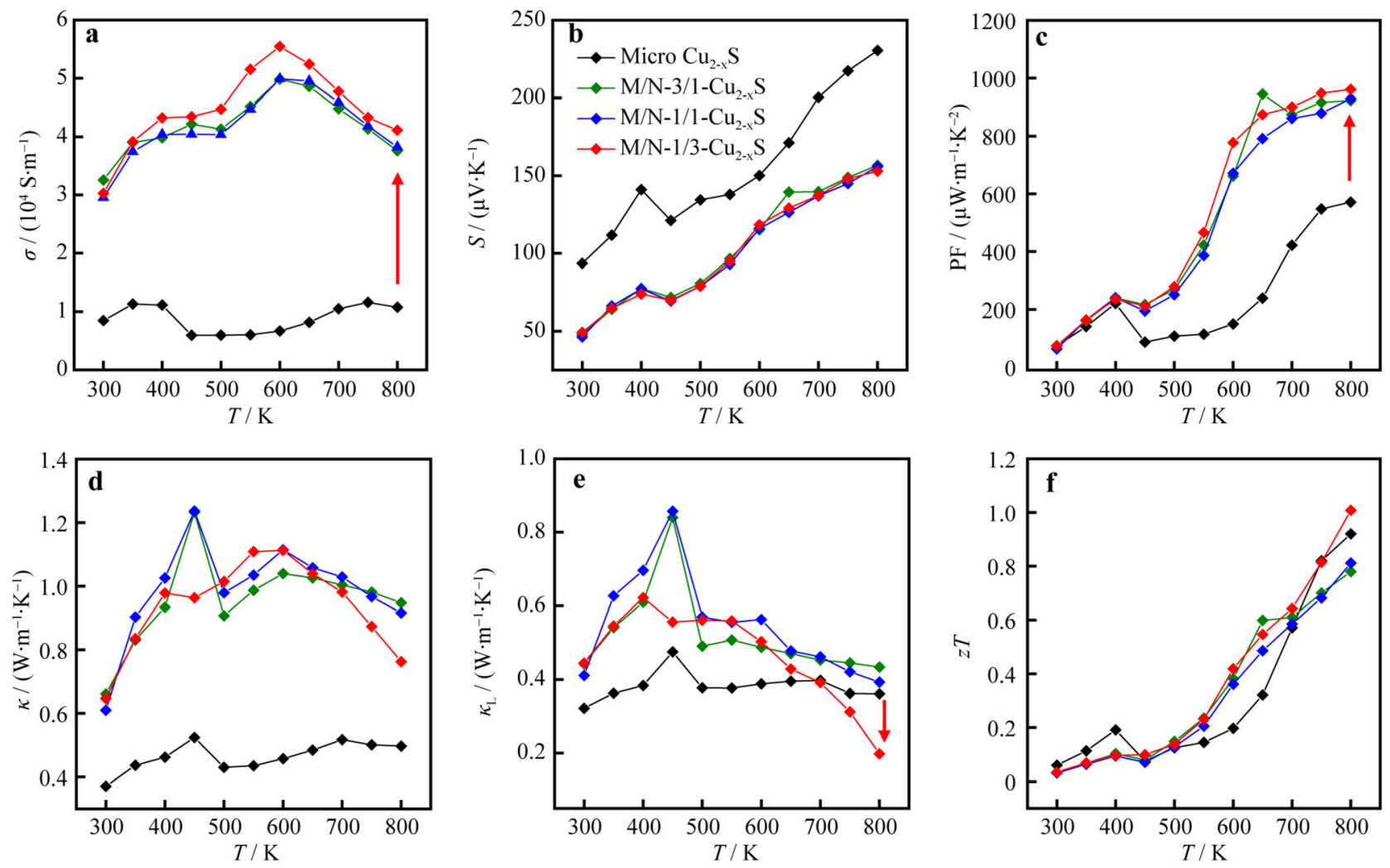

Fig. 5 TE properties of micro- $\mathrm{Cu}_{2-x} \mathrm{~S}$ and multiscale architecture-engineered $\mathrm{Cu}_{2-x} \mathrm{~S}$ samples in measured temperature (300-800 K): a $\sigma, \mathbf{b} S$, c PF, $\mathbf{d} \kappa, \mathbf{e} \kappa_{\mathrm{L}}$, and $\mathbf{f} z T$ 
Table 1 Measured and predicted TE parameters for micro- $\mathrm{Cu}_{2-x} \mathrm{~S}$ and multiscale architecture-engineered $\mathrm{Cu}_{2-x} \mathrm{~S}$ samples

\begin{tabular}{lllll}
\hline Samples & micron $\mathrm{Cu}_{2-x} \mathrm{~S}$ & $\mathrm{M} / \mathrm{N}-3 / 1-\mathrm{Cu}_{2-x} \mathrm{~S}$ & $\mathrm{M} / \mathrm{N}-1 / 1-\mathrm{Cu}_{2-x} \mathrm{~S}$ & $\mathrm{M} / \mathrm{N}-1 / 3-\mathrm{Cu}_{2-x} \mathrm{~S}$ \\
\hline$n_{\mathrm{H}}$ at $300 \mathrm{~K} /\left(10^{20} \mathrm{~cm}^{-3}\right)$ & 0.89 & 2.97 & 2.53 & 2.28 \\
$\mu_{\mathrm{H}}$ at $300 \mathrm{~K} /\left(\mathrm{cm}^{2} \cdot \mathrm{V}^{-1} \cdot \mathrm{s}^{-1}\right)$ & 5.95 & 6.85 & 7.28 & 8.28 \\
$m^{*}$ at $800 \mathrm{~K} / \mathrm{m}_{\mathrm{e}}$ & 1.4197 & 1.6277 & 0.81 & 0.2833 \\
$(z T)_{\max }$ at $800 \mathrm{~K}$ & 0.91 & 0.78 & 5.48 & 1.00 \\
$\rho /\left(\mathrm{g} \cdot \mathrm{cm}^{-3}\right)$ & 5.13 & 5.40 & 97.8 & 5.50 \\
$R / \%^{\mathrm{a}}$ & 91.6 & 96.3 & 98.2
\end{tabular}

${ }^{\mathrm{a}}$ With regard to theoretical density of $5.6 \mathrm{~g} \cdot \mathrm{cm}^{-3}$
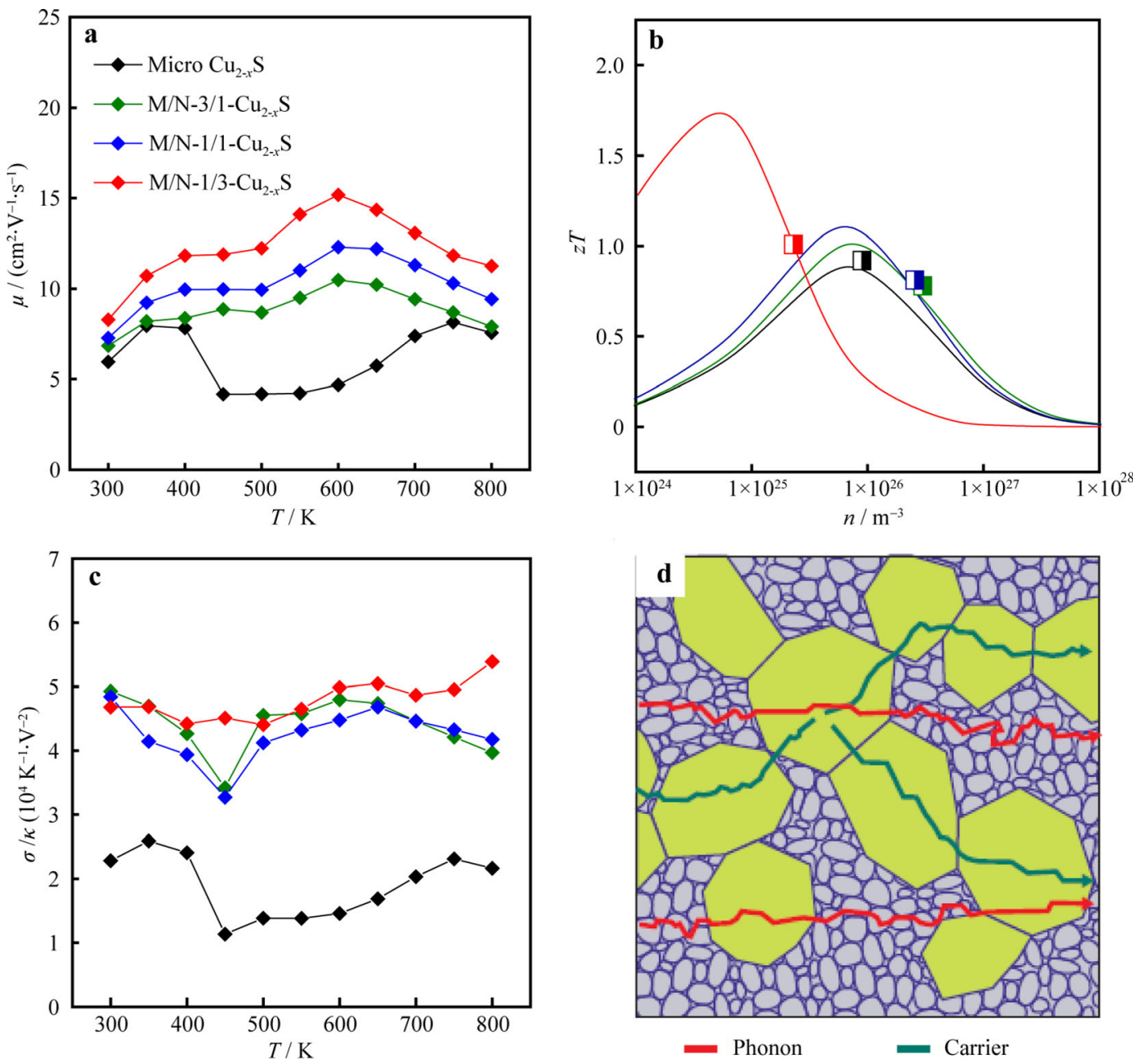

Fig. 6 a Optimized $\mu_{\mathrm{H}}$ of micro-Cu $\mathrm{Cu}_{2-x} \mathrm{~S}$ and multiscale architecture-engineered $\mathrm{Cu}_{2-x} \mathrm{~S}$ samples in temperature range between 300 and $800 \mathrm{~K}$; b $z T$ as a function of $n_{\mathrm{H}}$ at $800 \mathrm{~K}$, where symbols and solid curves are predicted from SPB model; c $\sigma / \kappa$ ratio of micro-Cu $\mathrm{Cu}_{2-x} \mathrm{~S}$ and multiscale architecture-engineered $\mathrm{Cu}_{2-x} \mathrm{~S}$ samples in temperature range between 300 and $800 \mathrm{~K}$; d presumed carrier and phonon transport paths in multiscale architecture-engineered $\mathrm{Cu}_{2-x} \mathrm{~S}$. Reproduced with permission from Ref. [6]. Copyright 2010, Springer Nature Limited

samples (Fig. 4b). The $\mathrm{Cu} / \mathrm{S}$ ratios in the multiscale architecture-engineered $\mathrm{Cu}_{2-x} \mathrm{~S}$ samples were calculated being $1.82,1.83$, and 1.85 with increasing the fraction of nanoparticles.

\subsection{Thermoelectric properties}

The temperature-dependent TE properties of micro- $\mathrm{Cu}_{2-x} \mathrm{~S}$ and multiscale architecture-engineered $\mathrm{Cu}_{2-x} \mathrm{~S}$ samples are 
shown in Fig. 5. The $\sigma$ values of the multiscale architecture-engineered $\mathrm{Cu}_{2-x} \mathrm{~S}$ are much higher than that of the micro- $\mathrm{Cu}_{2-x} \mathrm{~S}$ sample in the entire measured temperature range (Fig. 5a). Specifically, the $\sigma$ value of $\mathrm{M} / \mathrm{N}-1 / 3-$ $\mathrm{Cu}_{2-x} \mathrm{~S}$ sample reaches $4.1 \times 10^{4} \mathrm{~S} \cdot \mathrm{m}^{-1}$ at $800 \mathrm{~K}$, which is 4 times higher than that of the micro- $\mathrm{Cu}_{2-x} \mathrm{~S}$ sample. All samples exhibit positive $S$ with holes as the major charge carriers due to the formation of $\mathrm{Cu}$ ion vacancies. The $S$ of the multiscale architecture-engineered $\mathrm{Cu}_{2-x} \mathrm{~S}$ samples is lower than that of the micro- $\mathrm{Cu}_{2-x} \mathrm{~S}$ sample, with the opposite trend of $\sigma$ curves (Fig. 5b). While PF values of the multiscale architecture-engineered $\mathrm{Cu}_{2-x} \mathrm{~S}$ samples are higher than that of the micro- $\mathrm{Cu}_{2-x} \mathrm{~S}$ sample and increase with temperature rising after $450 \mathrm{~K}$. M/N-1/3- $\mathrm{Cu}_{2-x} \mathrm{~S}$ sample approaches a high PF value of $961 \mu \mathrm{W} \cdot \mathrm{m}^{-1} \cdot \mathrm{K}^{-2}$ at $800 \mathrm{~K}$ (Fig. 5c).

The $\kappa$ values of multiscale architecture-engineered $\mathrm{Cu}_{2-x} \mathrm{~S}$ samples increase at the low-temperature range and decrease when the temperature is above $600 \mathrm{~K}$ (Fig. 5d). $\kappa_{\mathrm{L}}$ is calculated by $\kappa_{\mathrm{L}}=\kappa-\kappa_{\mathrm{e}}$, where $\kappa_{\mathrm{e}}$ is the electronic thermal conductivity [51]. $\kappa_{\mathrm{L}}$ of the $\mathrm{M} / \mathrm{N}-1 / 3-\mathrm{Cu}_{2-x} \mathrm{~S}$ sample prominently minimizes to $0.2 \mathrm{~W} \cdot \mathrm{m}^{-1} \cdot \mathrm{K}^{-1}$ at $800 \mathrm{~K}$ (Fig. 5e). The $\mathrm{M} / \mathrm{N}-1 / 3-\mathrm{Cu}_{2-x} \mathrm{~S}$ sample possesses an improved $z T$ value of 1.0 at $800 \mathrm{~K}$, which is a $9 \%$ enhancement over the micro- $\mathrm{Cu}_{2-x} \mathrm{~S}$ sample at $800 \mathrm{~K}$ (Fig. 5f).

To understand our improved TE performance of the multiscale architecture-engineered $\mathrm{Cu}_{2-x} \mathrm{~S}$, the introduction of nanostructure and the formation of grain boundaries should be considered. $\sigma$ of the multiscale architectureengineered $\mathrm{Cu}_{2-x} \mathrm{~S}$ samples exhibits an obvious increase comparing to that of the micro- $\mathrm{Cu}_{2-x} \mathrm{~S}$ sample (Fig. 5a). To understand this phenomenon, $n_{\mathrm{H}}$ and $\mu_{\mathrm{H}}$ were measured at $300 \mathrm{~K}$ and further calculated by using a single parabolic band (SPB) model. The measured $n_{\mathrm{H}}$ and $\mu_{\mathrm{H}}$, the estimated effective mass $m^{*}$, and predicted maximum $z T$ of all samples are listed in Table 1 . The predicted $\mu_{\mathrm{H}}$ curves and the curves of $z T$ in comparison with the experimental points as a function of $n_{\mathrm{H}}$ are shown in Fig. $6 \mathrm{a}, \mathrm{b}$, respectively. The results show that $\mu_{\mathrm{H}}$ of the multiscale architecture-engineered $\mathrm{Cu}_{2-x} \mathrm{~S}$ samples has been enhanced rather than $n_{\mathrm{H}}$. According to $\sigma=n_{\mathrm{H}} \cdot \mathrm{e} \cdot \mu_{\mathrm{H}}$ (where $\mathrm{e}$ is a charge of the electron), the obvious increase of $\sigma$ should be derived from the enhancement of $\mu_{\mathrm{H}}$ (Fig. 6a) [28]. The lower $m^{*}$ of the $\mathrm{M} / \mathrm{N}-1 / 3-\mathrm{Cu}_{2-x} \mathrm{~S}$ sample leads to higher $\mu_{\mathrm{H}}$ as well. The $\sigma$ also increases with expending the fraction of nanoparticles, which is possibly due to the potential energy filtering effect at the micro/nano boundaries [52]. Figure S3 displays that the grain sizes of the annealed multiscale architecture-engineered $\mathrm{Cu}_{2-x} \mathrm{~S}$ reduce as the fraction of nanoparticles increasing. The density of samples has a negligible effect on this result since the relative densities for all multiscale architecture-engineered $\mathrm{Cu}_{2-x} \mathrm{~S}$ samples are almost the same, as listed in Table 1 . In Fig. $6 \mathrm{~b}, n_{\mathrm{H}}$ of the $\mathrm{M} / \mathrm{N}-1 / 3-\mathrm{Cu}_{2-x} \mathrm{~S}$ sample is closer to its respective optimum than the micro- $\mathrm{Cu}_{2-x} \mathrm{~S}$ sample, which is consistent with the particular $\mathrm{M} / \mathrm{N}-1 / 3-\mathrm{Cu}_{2-x} \mathrm{~S}$ sample measured having greater $z T$ value than the micro$\mathrm{Cu}_{2-x} \mathrm{~S}$ sample. As shown in Fig. $6 c$, the $\sigma / \kappa$ ratio of M/N$1 / 3-\mathrm{Cu}_{2-x} \mathrm{~S}$ sample increases at $700-800 \mathrm{~K}$, which means the reduction of $\kappa$ has more influences than the promotion of $\sigma$ at this temperature region. The presumed phonon (red) and carrier (green) transport paths in the multiscale architecture-engineered $\mathrm{Cu}_{2-x} \mathrm{~S}$ are shown in Fig. 6d. The nanoparticles in the multiscale architecture enhancing phonon scattering results in the reduction of $\kappa_{\mathrm{L}}$. The underlying mechanism is that grain boundaries can scatter phonons more effectively than carriers [53]. The presently enhanced $z T$ value at $700-800 \mathrm{~K}$ should be mainly attributed to the reduced $\kappa_{\mathrm{L}}$.

\section{Conclusion}

In conclusion, the multiscale architecture-engineered $\mathrm{Cu}_{2-x} \mathrm{~S}$ is fabricated by an optimized ambient wet chemical method combining mechanical mixing and SPS technology. The enhanced TE performance derives from the introduction of nanostructure and the formation of new grain boundaries. The formation of grain boundaries induces the potential energy filtering effect leading to an enhanced $\sigma$ in the multiscale architecture-engineered $\mathrm{Cu}_{2-x} \mathrm{~S}$. Nanostructure and small grain sizes enhance phonon scattering and result in the reduction of $\kappa_{\mathrm{L}}$. The peak $z T$ value of 1.0 at $800 \mathrm{~K}$ can be achieved in the $\mathrm{M} / \mathrm{N}-$ $1 / 3-\mathrm{Cu}_{2-x} \mathrm{~S}$ sample, which is competitive among the reported $\mathrm{Cu}_{2-x} \mathrm{~S}$ or its composites at the same temperature. This work indicates our method is low cost and practical for the preparation of the multiscale architecture-engineered $\mathrm{Cu}_{2-x} \mathrm{~S}$, which shows high potential for thermoelectric applications.

Acknowledgements This study was financially supported by the National Natural Science Foundation of China (Nos. 51702091 and 51702046), the College Outstanding Young Scientific and Technological Innovation Team of Hubei province (No. T201922), the Special Funding of Preventing the Spread of COVID-19, Hubei University of Education (No. 20XGZX20), Fok Ying-Tong Education Foundation of China (No. 171041), the Program for Professor of Special Appointment (Eastern Scholar) at Shanghai Institutions of Higher Learning, State Key Laboratory for Modification of Chemical Fibers and Polymer Materials, Donghua University. The authors thank Prof. Zhi-Gang Chen and Dr. Wei-Di Liu from the Centre for Future Materials, University of Southern Queensland for critical reading of the manuscript. 


\section{References}

[1] Shi XL, Zou J, Chen ZG. Advanced thermoelectric design: from materials and structures to devices. Chem Rev. 2020;120(15): 7399

[2] Shi X, Chen LD, Uher C. Recent advances in high-performance bulk thermoelectric materials. Int Mater Rev. 2016;61(6):379.

[3] Service RF. Temperature rises for devices that turn heat into electricity. Science. 2004;306:806.

[4] Liu WD, Yang L, Chen ZG, Zou J. Promising and eco-friendly $\mathrm{Cu}_{2} \mathrm{X}$-based thermoelectric materials: progress and applications. Adv Mater. 2020;32(8):e1905703.

[5] Bell LE. Cooling, heating, generating power, and recovering waste heat with thermoelectric systems. Science. 2008; 321(5895): 1457

[6] Li JF, Liu WS, Zhao LD, Zhou M. High-performance nanostructured thermoelectric materials. NPG Asia Mater. 2010;2(4): 152.

[7] Li DL, Gong YN, Chen YX, Lin JM, Khan Q, Zhang YP, Li Y, Zhang H, Xie HP. Recent progress of two-dimensional thermoelectric materials. Nano-Micro Lett. 2020;12(1):36.

[8] Zhang X, Zhao LD. Thermoelectric materials: energy conversion between heat and electricity. J Materiomics. 2015;1(2):92.

[9] Zeier WG, Zevalkink A, Gibbs ZM, Hautier G, Kanatzidis MG, Snyder GJ. Thinking like a chemist: intuition in thermoelectric materials. Angew Chem Int Ed. 2016;55(24):6826.

[10] Wang Y, Hong M, Liu WD, Shi XL, Xu SD, Sun Q, Gao H, Lu $\mathrm{S}$, Zou J, Chen ZG. $\mathrm{Bi}_{0.5} \mathrm{Sb}_{1.5} \mathrm{Te}_{3}$ /PEDOT:PSS-based flexible thermoelectric film and device. Chem Eng J. 2020;397:125360.

[11] Wang Y, Liu WD, Shi XL, Hong M, Wang LJ, Li M, Wang H, Zou J, Chen ZG. Enhanced thermoelectric properties of nanostructured n-type $\mathrm{Bi}_{2} \mathrm{Te}_{3}$ by suppressing $\mathrm{Te}$ vacancy through non-equilibrium fast reaction. Chem Eng J. 2020;391:123513.

[12] Tan GJ, Zhao LD, Kanatzidis MG. Rationally designing high-performance bulk thermoelectric materials. Chem Rev. 2016;116(19):12123.

[13] Si KP, Meng LJ, Gong YJ. Fabrication methods and properties of two-dimensional group VB transition metal dichalcogenides. Chin J Rare Met. 2019;43(11):1164.

[14] Dargusch M, Liu WD, Chen ZG. Thermoelectric generators: alternative power supply for wearable electrocardiographic systems. Adv Sci. 2020;7(18):2001362.

[15] Liao WW, Yang L, Chen J, Zhou DL, Qu XL, Zheng K, Han G, Zhou JB, Hong M, Chen ZG. Realizing Bi-doped $\alpha-\mathrm{Cu}_{2} \mathrm{Se}$ as a promising near-room-temperature thermoelectric material. Chem Eng J. 2019;371:593.

[16] Liu WD, Shi XL, Moshwan R, Yang L, Chen ZG, Zou J. Solvothermal synthesis of high-purity porous $\mathrm{Cu}_{1.7} \mathrm{Se}$ approaching low lattice thermal conductivity. Chem Eng J. 2019;375:121996.

[17] Liu WD, Wang DZ, Liu QF, Zhou W, Shao ZP, Chen ZG. High-performance GeTe-based thermoelectrics: from materials to devices. Adv Energy Mat. 2020;10(19):2000367.

[18] Qiu PF, Shi X, Chen LD. Cu-based thermoelectric materials. Energy Storage Mat. 2016;3:85.

[19] Wei TR, Qin YT, Deng TT, Song QF, Jiang BB, Liu RH, Qiu PF, Shi X, Chen LD. Copper chalcogenide thermoelectric materials. Sci China Mat. 2018;62(1):8.

[20] Ge ZH, Zhao LD, Wu D, Liu XY, Zhang BP, Li JF, He JQ. Low-cost, abundant binary sulfides as promising thermoelectric materials. Mat Today. 2016;19(4):227.

[21] Chen XQ, Yang JP, Wu T, Li L, Luo W, Jiang W, Wang LJ. Nanostructured binary copper chalcogenides: synthesis strategies and common applications. Nanoscale. 2018;10(32):15130.
[22] Dennler G, Chmielowski R, Jacob S, Capet F, Roussel P, Zastrow S, Nielsch K, Opahle I, Madsen GKH. Are binary copper sulfides/selenides really new and promising thermoelectric materials? Adv. Energy Mat. 2014;4(9):1301581.

[23] Roy P, Srivastava SK. Nanostructured copper sulfides: synthesis, properties and applications. CrystEngComm. 2015;17(41):7801.

[24] Powell AV. Recent developments in earth-abundant copper-sulfide thermoelectric materials. J Appl Phys. 2019;126(10): 100901.

[25] Liu WD, Yang L, Chen ZG. $\mathrm{Cu}_{2} \mathrm{Se}$ thermoelectrics: property, methodology, and device. Nano Today. 2020;35:100938.

[26] Zhu J, Yu XC, Wang SM, Dong WW, Hu LH, Fang XD, Dai SY. Application of $\mathrm{Cu}_{2} \mathrm{~S}$ counter electrode in quantum dot-sensitized solar cells. Acta Phys-Chim Sin. 2013;29(3):533.

[27] Ma MZ, Yao Y, Wu Y, Yu Y. Progress and prospects of transition metal sulfides for sodium storage. Adv Fiber Mater. 2020; 2:314.

[28] Zhou XY, Yan YC, Lu X, Zhu HT, Han XD, Chen G, Ren ZF. Routes for high-performance thermoelectric materials. Mater Today. 2018;21(9):974.

[29] Xu SD, Hong M, Shi XL, Li M, Sun Q, Chen QX, Dargusch M, Zou J, Chen ZG. Computation-guided design of high-performance flexible thermoelectric modules for sunlight-to-electricity conversion. Energy Environ Sci. 2020;13(10):3480.

[30] Zhao LL, Wang XL, Fei FY, Wang JY, Cheng ZX, Dou SX, Wang J, Snyder GJ. High thermoelectric and mechanical performance in highly dense $\mathrm{Cu}_{2-x} \mathrm{~S}$ bulks prepared by a melt-solidification technique. J Mater Chem A. 2015;3(18):9432.

[31] Liu WD, Shi XL, Gao H, Moshwan R, Xu SD, Wang Y, Yang L, Chen ZG, Zou J. Kinetic condition driven phase and vacancy enhancing thermoelectric performance of low-cost and eco-friendly $\mathrm{Cu}_{2-x}$ S. J Mater Chem C. 2019;7(18):5366.

[32] Qiu PF, Zhu YQ, Qin YT, Shi X, Chen LD. Electrical and thermal transports of binary copper sulfides $\mathrm{Cu}_{x} \mathrm{~S}$ with $x$ from 1.8 to 1.96. APL Mater. 2016;4(10):104805.

[33] Zhang YM, Shen XC, Yan YC, Wang GW, Wang GY, Li JY, Lu $\mathrm{X}$, Zhou XY. Enhanced thermoelectric performance of ternary compound $\mathrm{Cu}_{3} \mathrm{PSe}_{4}$ by defect engineering. Rare Met. 2020; 39(11): 1256.

[34] He Y, Day T, Zhang T, Liu H, Shi X, Chen L, Snyder GJ. High thermoelectric performance in non-toxic earth-abundant copper sulfide. Adv Mater. 2014;26(23):3974.

[35] Mao T, Qiu PF, Liu J, Du XL, Hu P, Zhao KP, Ren DD, Shi X, Chen LD. Good stability and high thermoelectric performance of Fe doped $\mathrm{Cu}_{1.08}$ S. Phys Chem Chem Phys. 2020;22(14):7374.

[36] Ge ZH, Liu XY, Feng D, Lin JY, He JQ. High-performance thermoelectricity in nanostructured earth-abundant copper sulfides bulk materials. Adv Energy Mater. 2016;6(16):1600607.

[37] Yao Y, Zhang BP, Pei J, Liu YC, Li JF. Thermoelectric performance enhancement of $\mathrm{Cu}_{2} \mathrm{~S}$ by Se doping leading to a simultaneous power factor increase and thermal conductivity reduction. J Mater Chem C. 2017;5(31):7845.

[38] Tang HC, Sun FH, Dong JF, Asfandiyar K, Zhuang HL, Pan Y, Li JF. Graphene network in copper sulfide leading to enhanced thermoelectric properties and thermal stability. Nano Energy. 2018;49:267.

[39] He Y, Lu P, Shi X, Xu F, Zhang T, Snyder GJ, Uher C, Chen L. Ultrahigh thermoelectric performance in mosaic crystals. Adv Mater. 2015;27(24):3639.

[40] Zhu GJ, Guo R, Luo W, Kun Liu HK, Jiang W, Dou SX, Yang JP. Boron doping-induced interconnected assembly approach for mesoporous silicon oxycarbide architecture. Natl Sci Rev. 2020. https://doi.org/10.1093/nsr/nwaa152.

[41] Meng QL, Kong S, Huang ZW, Zhu YH, Liu HC, Lu X, Jiang P, Bao XH. Simultaneous enhancement in the power factor and 
thermoelectric performance of copper sulfide by $\mathrm{In}_{2} \mathrm{~S}_{3}$ doping. J Mater Chem A. 2016;4(32):12624.

[42] Biswas K, He JQ, Blum ID, Wu CI, Hogan TP, Seidman DN, Dravid VP, Kanatzidis MG. High-performance bulk thermoelectrics with all-scale hierarchical architectures. Nature. 2012; 489(7416):414.

[43] Chen XQ, Zhang H, Zhao YY, Liu WD, Dai W, Wu T, Lu XF, Wu C, Luo W, Fan YC, Wang LJ, Jiang W, Chen ZG, Yang JP. Carbon-encapsulated copper sulfide leading to enhanced thermoelectric properties. ACS Appl Mater Interfaces. 2019;11(25): 22457.

[44] Chen XQ, Li Z, Dou SX. Ambient facile synthesis of gram-scale copper selenide nanostructures from commercial copper and selenium powder. ACS Appl Mater Interfaces. 2015;7(24): 13295.

[45] Okamoto K, Kawai S. Electrical conduction and phase transition of copper sulfides. Jpn J Appl Phys. 1973;12(8):1130.

[46] Wang LW. High chalcocite $\mathrm{Cu}_{2} \mathrm{~S}$ : a solid-liquid hybrid phase. Phys Rev Lett. 2012;108(8):085703.

[47] Tang YQ, Ge ZH, Feng J. Synthesis and thermoelectric properties of copper sulfides via solution phase methods and spark plasma sintering. Crystals. 2017;7(5):141.
[48] Tang YQ, Zhang K, Ge ZH, Feng J. Facile synthesis and thermoelectric properties of $\mathrm{Cu}_{1.96} \mathrm{~S}$ compounds. J Solid State Chem. 2018;265:140.

[49] Chen L, Liu J, Wang Y, Zhang Z. Characterization of $\alpha-\mathrm{Cu}_{2} \mathrm{Se}$ fine structure by spherical-aberration-corrected scanning transmission electron microscope. Acta Phys-Chim Sin. 2019;35(2): 139.

[50] Chen XQ, Li Z, Bai Y, Sun Q, Wang LZ, Dou SX. Room-temperature synthesis of $\mathrm{Cu}_{2-x} \mathrm{E}(\mathrm{E}=\mathrm{S}, \mathrm{Se})$ nanotubes with hierarchical architecture as high-performance counter electrodes of quantum-dot-sensitized solar cells. Chem-Eur J. 2015;21(3):1055.

[51] Shen XC, Zhang X, Zhang B, Wang GY, He J, Zhou XY. Optimizing thermoelectric properties of BiSe through $\mathrm{Cu}$ additive enhanced effective mass and phonon scattering. Rare Met. 2020;39(12):1374.

[52] Zhao LD, Zhang BP, Liu WS, Li JF. Effect of mixed grain sizes on thermoelectric performance of $\mathrm{Bi}_{2} \mathrm{Te}_{3}$ compound. J Appl Phys. 2009;105(2):023704.

[53] Zhu TJ, Liu YT, Fu CG, Heremans JP, Snyder JG, Zhao XB. Compromise and synergy in high-efficiency thermoelectric materials. Adv Mater. 2017;29(14):1605884. 